\title{
Ilha da Tartaruga: Gamificação na Educação Ambiental
}

\author{
Maria de Jesus Costa1, Sara Stephane Moreira Torres1 \\ 1 Instituto Universidade Virtual - Universidade Federal do Ceará (UFC) \\ Fortaleza - CE - Brasil \\ suzymaria.costa@gmail.com, sarastephane@gmail.com
}

\begin{abstract}
This paper approaches the principles of Environmental Education, the concepts and characteristics of gamification used in the educational area. It's structured as a case study with the intent of describing the application of gamification in the learning object(LO) Ilha da Tartaruga, that uses this approach to generate a bigger engagement and learning in the perspective of environmental education. Its development goes through the education character in the environmental area, the description of the LO (used as a study object) and the process of gamification applied. The paper concludes with an opinion about the results of the process applied in the LO and a thought about the next steps to the research.
\end{abstract}

Resumo. Este artigo aborda os princípios da Educação Ambiental, conceitos e características da gamificação aplicados na área educacional. Está estruturado como um estudo de caso no intuito de descrever a aplicação da gamificação no objeto de aprendizagem (OA) Ilha da Tartaruga, que usa tal abordagem para gerar um maior engajamento e aprendizagem no âmbito da educação ambiental. Seu desenvolvimento percorre o caráter educacional da área ambiental, a descrição do $O A$ (usado como objeto do estudo) e o processo de gamificação aplicado. $O$ artigo conclui-se com um parecer sobre os resultados do processo aplicado no OA e uma reflexão sobre os próximos passos na pesquisa.

\section{Introdução}

A relação entre conservação de recursos naturais e desenvolvimento sustentável é amplamente amparada pelo campo de atuação da Educação Ambiental. Incorpora uma sequência de ações, que visam fomentar discussões pertinentes sobre a qualidade de vida dos indivíduos, e como traçar estratégias para criar essa relação de conservação e desenvolvimento [Santos et al. 2016]. Assim, paradigmas educacionais, para o preparo de indivíduos com competências e habilidades capazes de adequar-se às mudanças contínuas e propor soluções sustentáveis, são analisados [Santos et al 2016].

Nesse contexto, também é considerado a geração de indivíduos que nasceram em meio às novas tecnologias, e as usam em suas práticas diárias naturalmente. Um termo muito utilizado para referir-se a essa geração é de "nativos digitais" [Prensky 2012]. Para Prensky esses jovens possuem características distintas das gerações anteriores, pois nasceram com a 
tecnologia a seu dispor, consolidando seu uso em todas as suas atividades diárias. O que ressalta a necessidade de conectar-se a uma perspectiva mais interativa, pautada nas novas tecnologias e que ressignifica os recursos voltados para a educação. Pois as mudanças tecnológicas ocorridas provocaram alterações consideráveis no processo de como os jovens pensam, aprendem e processam as informações [Prensky 2012].

Sobre estratégias de aprendizagem, a gamificação se mostra um recurso bastante alinhado com a necessidade de integrar interatividade, paradigmas educacionais coerentes para as novas gerações e tecnologias. A gamificação possui como princípio a adaptação de elementos dos jogos, para aplicação em outros contextos, como produtos e serviços, que não necessariamente são focados em jogos, mas com a intenção de promover a motivação e o comportamento do indivíduo [Vianna et al 2013]. Ainda para Vianna et al. (2013), a gamificação pode despertar emoções positivas e explorar aptidões, ligadas às recompensas virtuais ou físicas ao se cumprir determinada tarefa. Devido a isso, torna-se uma estratégia usada em circunstâncias que exijam a criação ou a adaptação da experiência do usuário a um produto, serviço ou processo que vise gerar um maior engajamento.

No âmbito da elaboração de ações da educação ambiental, que promovem discussões sobre conservação e desenvolvimento, voltadas para o público nativo digital. Uma questão a ser investigada é a de como adaptar atividades práticas da educação ambiental para um objeto de aprendizagem (OA) utilizando os princípios da gamificação.

Neste contexto, o presente artigo tem como propósito apresentar a aplicação da gamificação, empregada com a intenção de gerar um maior engajamento e aprendizagem no âmbito da educação ambiental. Utilizando o objeto de aprendizagem Ilha da Tartaruga 1 como objeto de um estudo de caso, por reproduzir tal abordagem da gamificação.

\section{Princípios da Educação Ambiental}

A questão ambiental ganhou espaço no contexto educacional, pois a educação ambiental projeta as relações cotidianas entre seres humanos, espécies animais e vegetais, bem como procura soluções para interações nocivas e/ou aperfeiçoar interações positivas. Em uma perspectiva que garanta a possibilidade de se viver dignamente. É um processo pedagógico e político, fundamental e que caracteriza a sua inserção no campo educacional [Reigota $2017]$.

Ainda segundo o autor, o estado de desequilíbrio ambiental é uma questão da sociedade. O que evidencia o objetivo da educação ambiental em favorecer e estimular possibilidades de se estabelecer coletivamente uma conciliação entre sociedade e meio ambiente. Fomentando a articulação entre o desenvolvimento sustentável e a conservação dos recursos naturais [Reigota 2017].

É considerado então, que com esses princípios fundamentais a educação ambiental deve ser entendida como educação política, no sentido de que ela reivindica e prepara os indivíduos. Para exigir e construir uma sociedade com justiça social, cidadanias, autogestão e ética nas relações sociais e com o meio ambiente [Reigota 2017].

1 Aplicação desenvolvida pelo grupo Cactools. Fonte: <https://cactools.wordpress.com/> 


\section{Objeto de Aprendizagem Ilha da Tartaruga}

A Ilha da Tartaruga é caracterizada como um objeto de aprendizagem (OA), de acordo com o Learning Objects Metadata Workgroup, Objetos de Aprendizagem (Learning Objects) podem ser definidos como "qualquer entidade, digital ou não digital, que possa ser utilizada, reutilizada ou referenciada durante o aprendizado suportado por tecnologias" [IEE LTSC 2007]. O OA foi desenvolvido para o Instituto Verdeluz2, um projeto sem fins lucrativos que tem por visão a busca por uma Gestão Ambiental Sustentável. O Verdeluz é engajado em modificar a situação de negligência para com o meio ambiente e promover a participação de diversas comunidades de Fortaleza no estado do Ceará, através de programas desenvolvidos em cinco frentes: Educação Ambiental; Reciclagem e Gestão de Resíduos Sólidos; Cuidado de Tartarugas; Cultura e Arte e; Agroecologia Urbana [INSTITUTO VERDELUZ 2017].

O Verdeluz desenvolve, entre vários projetos, a prática da educação ambiental que tem como foco crianças e adolescentes. $\mathrm{O}$ instituto visa incentivar essa educação nos jovens para desenvolver o crescimento de cidadãos ecologicamente conscientes. No entanto o instituto encontrou dificuldade em fazer com que os jovens propaguem os conhecimentos adquiridos durante a participação nos projetos, e que eles levassem a aprendizagem de sala de aula e/ou de aula de campo para a rotina deles [ Almeida 2017].

A Ilha da Tartaruga surge nesse contexto com o intuito de solucionar essas dificuldades do Verdeluz. O OA tem como objetivo tornar esses jovens em agentes ecologicamente conscientes e também ativos. Sendo uma aplicação online para ser utilizada em computadores (desktop), os alunos podem acessar e utilizá-la como uma extensão da sala de aula, de forma que todos os usuários terão acesso a um mundo compartilhado. É apresentada uma plataforma visual onde o usuário irá interagir com o sistema com a finalidade de cumprir tarefas propostas no mundo real, que depois serão convertidas para $o$ virtual na forma de recursos dentro da aplicação.

A aplicação é mantida pelos próprios alunos com dados baseados em suas rotinas, de acordo com os conceitos de preservação ambiental estudados em sala de aula, gerando integração entre práticas desenvolvidas em aulas em sala e/ou campo. O propósito dessa integração entre o ambiente virtual e mundo real é o de gerar uma metáfora de representação das ações coletivas, pois há a modificação da aparência da ilha no OA por um trabalho conjunto dos alunos e portanto no mundo real o coletivo pode também modificar para melhor o ambiente ao seu redor.

Ao entrar no OA, o ambiente simula um conjunto de ilhas, em que cada usuário tem a sua residência no ambiente, inicialmente a ilha sofre com a degradação do meio ambiente, animais sendo ameaçados; desmatamento em prol de monoculturas; não tratamento de resíduos urbanos, etc (Figura 1). Interações positivas de preservação ocasionaram melhorias na ilha, tornando a relação de convivência da comunidade com o ambiente mais sustentável (Figura 2). 


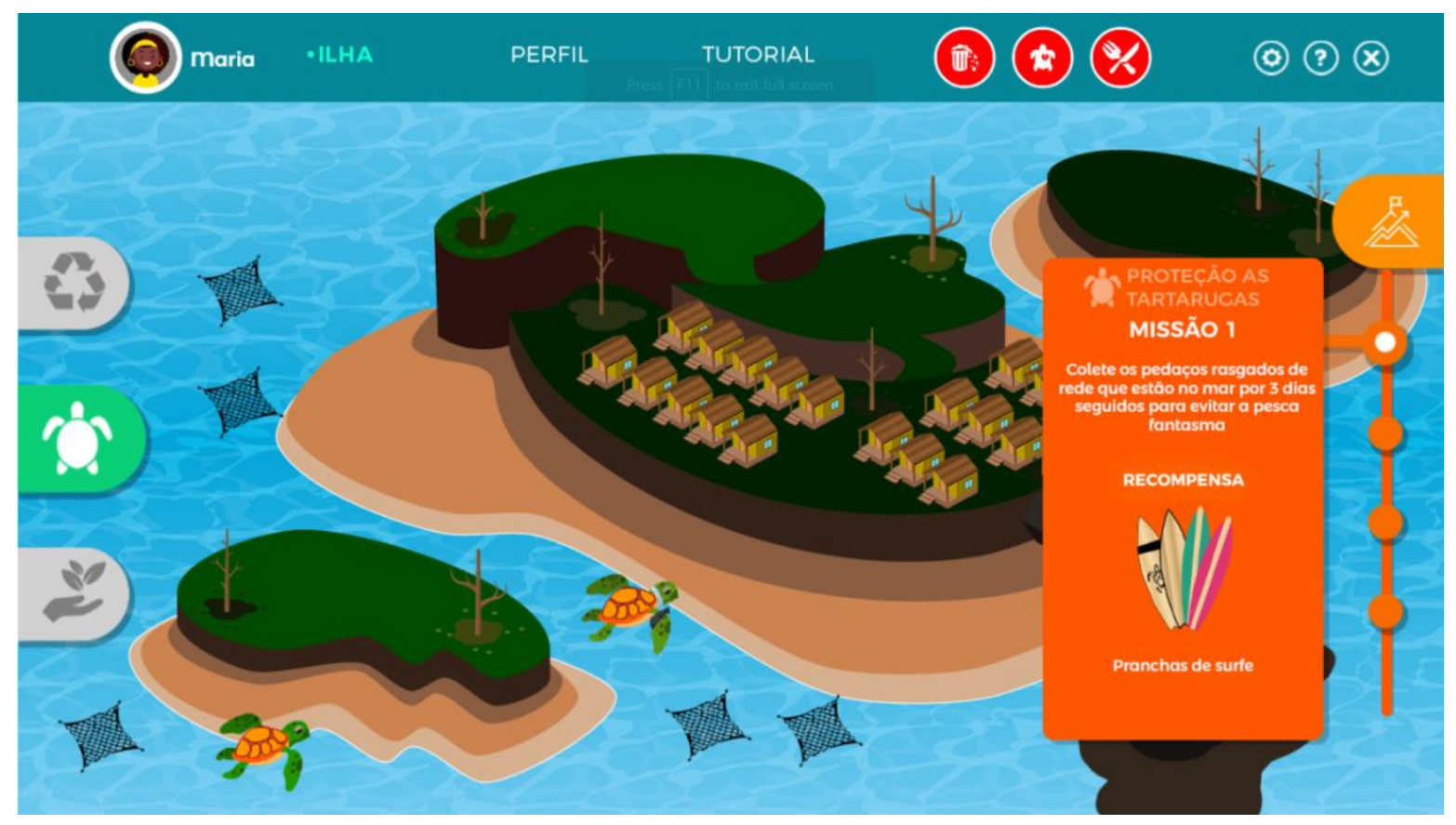

Figura 1. Ilha da Tartaruga, antes das interações da comunidade de usuários.

\section{Aplicação do Processo de Gamificação}

Aplicando a abordagem de gamificação adotada por Zichermann e Cunningham (2011), algumas ferramentas são usadas como base que constitui os critérios para a produção de respostas estéticas significativas nos produtos que passam pelo processo de gamificação. Algumas dessas ferramentas são encontradas na Ilha da Tartaruga, como:

Níveis: Servem como uma forma de controle do progresso das habilidades propostas ao desenvolvimento na atividade, como etapas que indicam o progresso do jogador dentro do jogo; A ilha da Tartaruga representa esses níveis em descendência, quanto mais limpa a ilha menor é o nível de poluição, quando se zera os 3 módulos de níveis, a ilha está em seu melhor estado de sustentabilidade.

Integração: é uma ferramenta que está associada ao processo de assimilação da narrativa e do seu ambiente, a partir de elementos narrativos que apresentam aspectos/ferramentas do jogo, cativando, encorajando e aprendendo sobre o jogador. Funciona como um parâmetro que indica o desenvolvimento do engajamento do jogador em seus primeiros passos no jogo. Na Ilha da Tartaruga a integração é representada pela mudança do visual da ilha na medida em que as missões vão sendo cumpridas, demonstrando um feedback visual de acordo com a narrativa da aplicação

Desafios e missões: são instruções direcionadas às ações da narrativa. Escolhas dadas pelo desenvolvedor aos usuários de como agir para atingir as metas do jogo. A Ilha da Tartaruga dispõe de um conjunto de quatro missões em cada módulo de interação, que buscam engajar os usuários para realização das ações de educação ambiental, pois cada direcionamento vai oferecer resultados mais eficazes na recuperação da ilha e/ou prover recompensas que também vão auxiliar as interações. 
Reforço e feedback: são ferramentas com a função de informar os jogadores, posicionando-os no espaço do jogo e dando-lhes um retorno quanto às suas ações. No OA essas ferramentas ainda retomam a importância das ações ambientais. Pois o OA em sua totalidade dá um feedback rápido sobre os resultados que poderiam ser vistos no mundo real, uma melhoria de difícil acompanhamento no contexto real. Esse contexto torna-se visível em ambiente controlado, reforçando o trabalho educacional (Figura 2).

Loops: agem como uma ferramenta que visa criar movimentos que mantenham as emoções relacionadas a um comportamento motivado no processo constante de engajamento com o jogo. Estão presentes no OA por meio das repetições das ações das missões, além de algumas missões serem de repetir ações por alguns dias, a não repetição delas e o descuido com a ilha acarretam numa regressão da evolução da ilha, podendo voltar ao seu estado de degrado inicial.

Personalização: compõe-se de elementos que criam uma identificação pessoal do jogador com o jogo, disponibilizadas de modo gradual, possibilitando a transformação de itens do sistema pelo jogador. Na ilha da tartaruga o aspecto da personalização está presente na característica de cada usuário possuir sua habitação própria dentro da ilha.

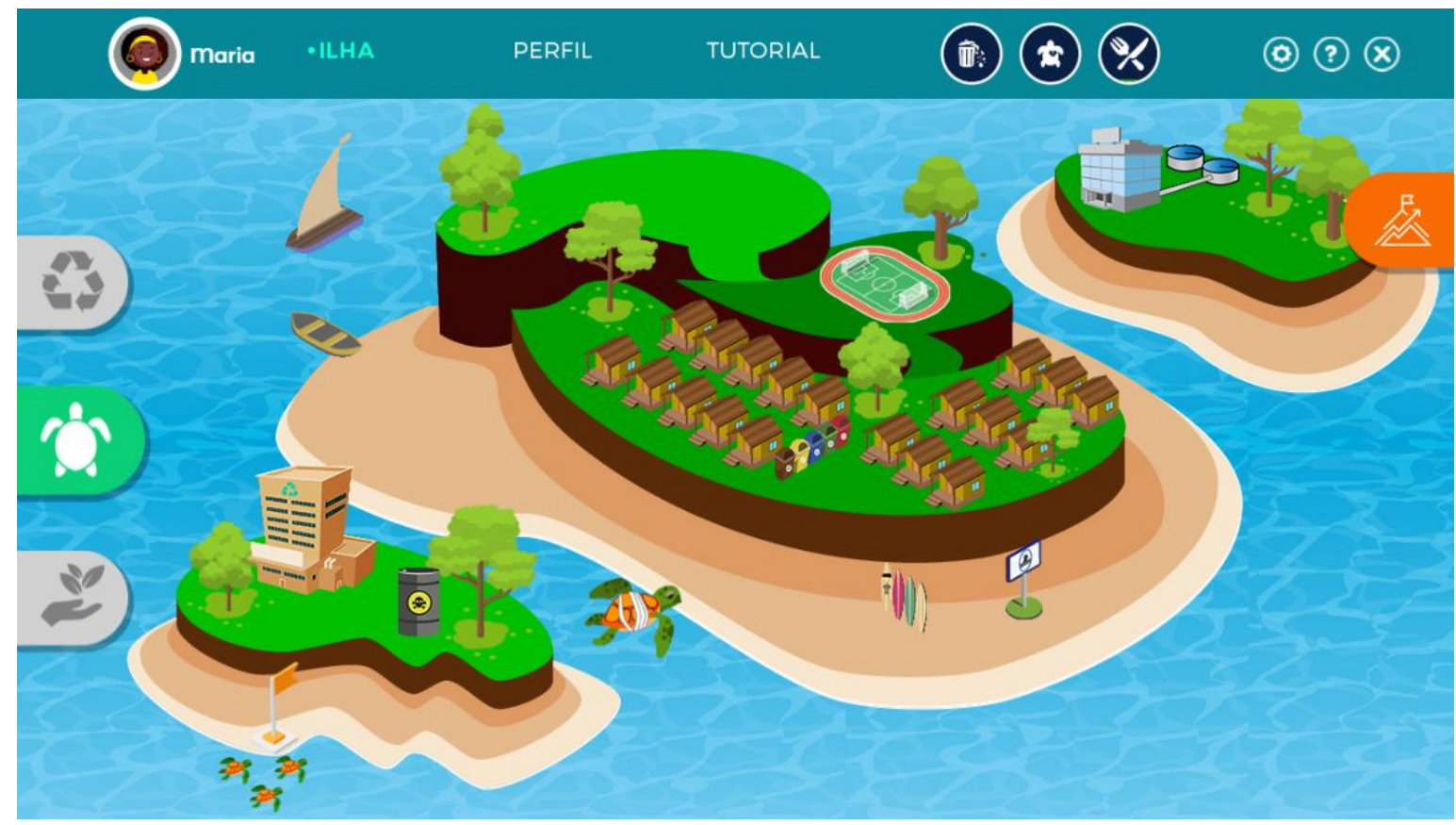

Figura 2. Ilha da Tartaruga, após interações da comunidade de usuários.

\section{Considerações Finais}

Baseado nos aspectos explorados no estudo de caso descrito, foram identificados vários conceitos discutidos pela educação ambiental, que foram mesclados às ferramentas de gamificação descritas por Zichermann e Cunningham (2011). Os aspectos de gamificação utilizados são necessários para a interpretação da narrativa ambiental dentro do OA. Desta 
forma os pilares para o desenvolvimento de uma recurso educacional que causem um maior engajamento, encontram-se presentes na Ilha da Tartaruga.

De acordo com Simões et al (2013) em um contexto educacional, aspectos dos jogos como repetição de experimentos, ciclos rápidos de resposta, diferentes possibilidades de caminhos, reconhecimento e recompensa, são extremamente significantes para a aprendizagem. Neste estudo, que explora a aplicação da abordagem da gamificação empregada com a intenção de gerar um maior engajamento e aprendizagem no âmbito da educação ambiental, foi observado que os aspectos supracitados estão incorporados na Ilha da Tartaruga.

Entretanto, mais etapas de pesquisas se fazem necessárias para evidenciar o cumprimento do objetivo do OA em gerar um maior engajamento e aprendizagem. A aplicação precisa ainda passar por etapas de validação com o seu público-alvo, para verificar a receptibilidade do recurso educacional.

\section{Referências}

Almeida, T. (2017), Entrevista sobre o Instituto Verdeluz [Entrevista concedida a] Grupo Cactools. Fortaleza.

IEE LTSC (2007), Disponível em: <http://tsc.ieee.org/wg12/index.html>, Acesso em: 25 abr. 2019.

Instituto Verdeluz (2019), Disponível em: <https://www.verdeluz.org/>, Acesso em: 25 abr. 2019.

Prensky, M. (2012) “Aprendizagem baseada em jogos digitais”, Senac, São Paulo.

Reigota, M. (2017) “O que é educação ambiental”, Editora Brasiliense, São Paulo.

Santos, A. M., Silva Junior, F. M., Lopes. E. R. N. (2016) "Gamificando a Educação Ambiental: O desafio Jogando Verde no Instituto Federal Baiano”, Revista Brasileira de Educação Ambiental, São Paulo.

Simões, J.; Díaz Redondo, R.; Vilas, R.F. (2013) “A social gamification framework for a K-6 learning platform”, Computers in Human Behavior, n.29, p.345-353, 2013.

Vianna, Y., Vianna, M., Medina, B., Tanaka, S. (2013) “Gamification”, In: Como reinventar empresas a partir de jogos, MJV Press, Rio de Janeiro.

Zichermann, G., Cunningham, C. (2011) "Gamification by Design: Implementing Game Mechanics in Web and Mobile Apps”, O’Reilly Media, Sebastopol, CA. 